\title{
Energy-related conditions and envelope properties for sustainable buildings
}

\author{
R. GERYŁO* \\ Instytut Techniki Budowlanej (ITB), 1 Filtrowa St., 00-611 Warsaw, Poland
}

\begin{abstract}
The assessment methodology for the sustainability of buildings is based on the analysis of environmental, social and economic performance. The main purpose of the paper is the presentation of energy-related conditions and envelope properties as well as methodology aspects. The first part of the paper presents the literature review on sustainability and zero-energy buildings. The second part is devoted to describe different energy indicators for the evaluation of primary energy requirements and energy characteristic. The last section describes the general methodology for characterization of energetic properties of the building envelope and gives examples from literature of the effect of applications in a building's envelope an aerogel based thermal insulation for higher thermal transmittance and a PCM for higher latent heat capacity with general description of results obtained by other authors. The crucial measure is the use of high thermal performance components for the building's envelopes combined with the heat storage potential. In the context of sustainability, energy related conditions constitute a new set of indicators for identifying the usefulness and the efficiency of new technologies.
\end{abstract}

Key words: sustainability of construction works; requirements development, primary energy, embodied energy, thermal performance, thermal stability.

\section{Introduction}

The concept of sustainable development originated during the final decades of the previous century and is still evolving. Overall energy consumption is considered to be a relevant part of the use of natural resources, and energy-related requirements for construction works plays a crucial role, as buildings use nearly $40 \%$ of total energy demand, resulting in almost $30 \%$ of greenhouse gas emissions. For this reason, the issue of energy efficiency has become a subject of discussion and research, both in terms of sustainability and development, providing the background for the standardisation and requirements in this field.

This paper has followed a number of other authors in considering whole life-cycle energy demand through the construction and management of buildings across its value chain, including material and construction products manufacturing, design and engineering services, onsite construction and service companies, property developers and facility managers and the end of life phase. Since energy use is closely related to cost, including the cost of emissions of greenhouse gases, economic evaluation is one of the possible dimensions for the optimisation of a building's energy efficiency measures. The cost-optimal level of building energy performance is determined as the lowest level of total energy-related cost during the expected lifespan.

Based on an analysis of results from more than 70 cases across Europe, Asia and North America, the use stage for typical buildings accounts for nearly $85 \%$ of total energy demand, as well as embodied energy in construction products and during the construction process accounts for nearly $15 \%$ of total energy demand $[1,2]$. A building's whole life-cycle energy performance

\footnotetext{
*e-mail: r.gerylo@itb.pl
}

can be significantly reduced by passive and active technologies application. However, in high energy-efficient buildings, the embodied energy can amount almost $45 \%$ of the energy demand during the operational stage $[3,4]$. The possible increase of embodied energy indicates that a more extensive methodology for setting a building's regulations may be required [5].

The papers reviewed have proposed various definitions for "zero energy buildings" (ZEB) including "life-cycle ZEB" (the embodied energy plus the operational energy) or "net ZEB" (the building-grid adaptability and the balance over a period of time) $[6,7,8]$. The zero energy building definition also includes the idea that the efficiency measures sequence includes the following steps:

- reducing the building's energy demand through low-energy technologies;

- use of renewable energy sources (available within the building or at the site and off site [9, 10].

Finally, low-energy technical solutions for envelopes in zero energy buildings are important including construction products with very high thermal resistance resulting in the high thermal performance of the envelope [11], especially aerogel-based [12-15] and heat storage construction products especially based on phase change materials, resulting in the high thermal stability of structures [16-18].

The main purpose of the paper is the presentation of energy-related conditions and envelope properties as well as methodology aspects for sustainable buildings and construction works. The first part of the paper presents the literature review on sustainability and zero-energy buildings. The second part is devoted to describe different energy indicators for the evaluation of primary energy requirements and energy characteristic. The last section describes the general methodology for characterization of energetic properties of the building envelope and gives examples from literature 
of the effect of applications in a building's envelope an aerogel based thermal insulation for higher thermal transmittance and a phase change material for higher latent heat capacity with general description of results obtained by other authors.

\section{Energy use in sustainability vs. development dimensions}

The implementation of the concept of sustainable development in the construction has led to the creation of several new fields of research referring to building materials and structures during their lifespan [19-21]. However, since the very beginning, a different emphasis was put on either development or sustainability aspects [22].

The different approaches could be described as follows:

- focused on equilibrium between economic, social and environmental sectors;

- focused on sustainability in the use of natural resources taking into account the needs of future generations;

- oriented on sustainable development as the increase now and in the future for the well-being for the greatest possible number of people [23].

The evolution of this topic with the emphasis on energy use can be traced to a paper [24]. The report presents the following rationale for the necessity of the change of global and local policies towards sustainability:

- the progressive degradation of the environment and reduction of natural resources and, as a consequence, the growing risk to progress,

- the expectation that a central sustainable development principle implies economic growth increasing the natural resource base.

From the standpoint of sustainability, the key energy-related issues were identified as follows:

- adequate energy supplies to meet global need,

- energy efficiency and conservation,

- protection against pollution related to energy use.

Modifying energy consumption patterns in building material production methods, construction works, buildings and urban environment is addressed in several parts of United Nation conferences and summits reports [25-27]. The need to further mainstream sustainable development at all levels and its specific dimensions - economic, social and environmental - and recognizing their interrelations have been identified. The adoption of energy efficiency programmes in building management is addressed in the framework, dealing with urban planning, including the revitalisation of older cities and neighbourhoods as well as the reduction of the negative impact of urban activity, including the more efficient use of energy within sustainable and resilient buildings.

Very early initiatives concerning the implementation of the sustainable development idea in construction works focused on the sustainability dimension [28]. The main issues for built environment sustainability have been related to environmental quality, including the reduction of inconvenience, risks and related costs as well as health, comfort and indoor environment quality.
This may also be confirmed by the outcome of international standardisation in this field. The international ISO and CEN standards cover life-cycle assessment of environmental, social and economic performance. The European standards are categorised in Fig. 1.

Despite the standardised nature of the aforementioned classification, in practice, a method based on a three-dimensional energy-related evaluation can be used to calculate the maximum value of the building's energy performance resulting in the minimum value of life-cycle cost and environmental impact [29], as shown in Fig. 2. With such a method, energy-related social performance (required indoor comfort: thermal and visual as

\section{Frameworks for the buildings assessment:}

General framework (EN 15643-1) [30]

Framework for assessment of environmental performance (EN 15643-2) [31]

Framework for assessment of social performance (EN 15643-3) [32]

Framework for assessment of economic performance (EN 15643-4) [33]

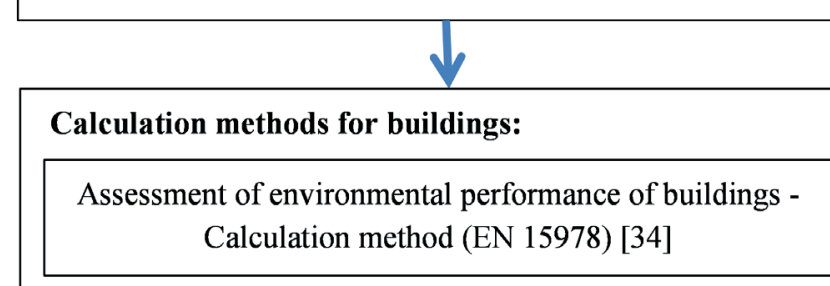

Assessment of social performance of buildings Calculation methodology (EN 16309) [35]

Assessment of economic performance of buildings Calculation methods (EN 16627) [36]

\section{Construction products assessment:}

Environmental Product Declarations - Core rules for the product category of construction products (EN 15804)

Some social aspects included under provision of EN 15804

Some economic aspects included under provision of EN 15804

Fig. 1. The groups of CEN on sustainability assessment in environmental, social and economic dimensions 


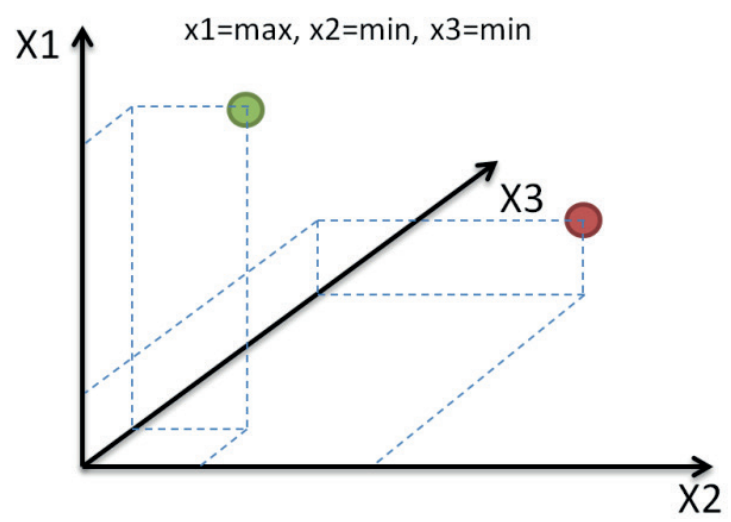

Fig. 2. Evaluation of the following dimensions: X1 - Building energy performance, X2 - Life-cycle costs, X3 - Life-cycle environmental impacts

well as air quality) is implicitly included as an input for energy performance. Since environmental impacts, e.g. emission of gases resulting from energy use, may be described in terms of cost, the assessment can be performed in two dimensions: energy performance versus life-cycle cost.

\section{Energy indicators and requirements development}

Due to the lack of a universally established common definition of sustainable development, as described in the previous section, there is no harmonised system for measuring general and specific aspects of the dimensions of sustainability and development. International standardisation has been focused on the sustainability of construction works vis-à-vis the development aspects, subject to requirements both obligatory, stipulated by the state and voluntary, as part of several environmental certification systems.

For energetic properties, as with other sustainable development aspects, different indicators were proposed to enable the assessment of sustainability, as well as indices, providing a numerical system for comparing variables that can change in respect to fixed standards in order to assess the development. The common accepted indicator is the total primary energy demand per reference unit (e.g. $\mathrm{m}^{2}$ of a building useful area or $\mathrm{kg}$ or $\mathrm{m}^{3}$ for construction products). The primary energy demand is divided into both non-renewable and renewable energy commodities, which cover fuel, as well as heat and power.

Primary energy is defined as energy derived directly from natural resources, taking account of the whole energy supply chain for energy delivery to a place of use: a manufacturing site, construction site or a building. Secondary energy commodities (fuels) can be produced from primary commodities. Fig. 3 shows the set of energy-related indicators commonly used for construction products.

The amount of energy can be determined by taking into account the construction products life cycle stages, as shown in Fig. 4, (standard designations A-D according to [37]).

The amount of energy related to the last stage of the life cycle (determined as negative values) shows the benefits of
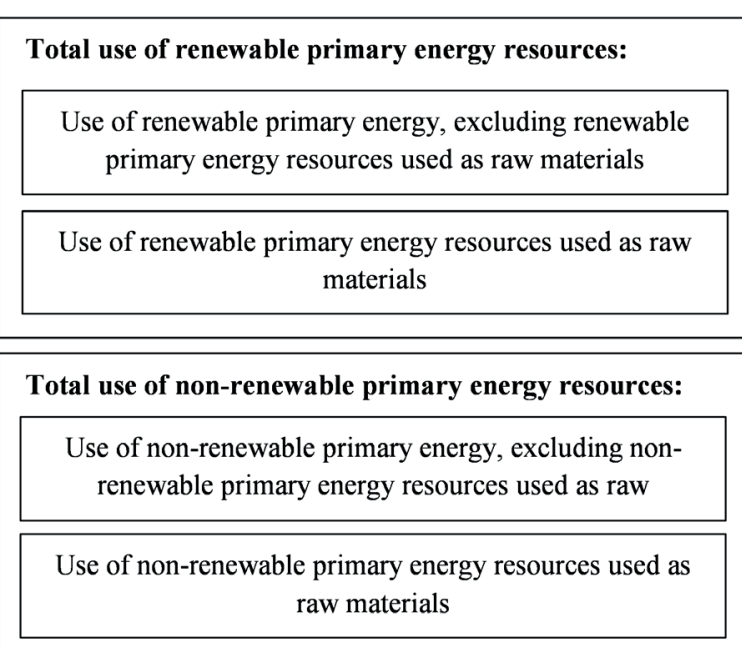

Total use of secondary fuels:

Use of renewable secondary fuels

Use of non-renewable secondary fuels

Fig. 3. The energy-related indicators commonly used for construction products

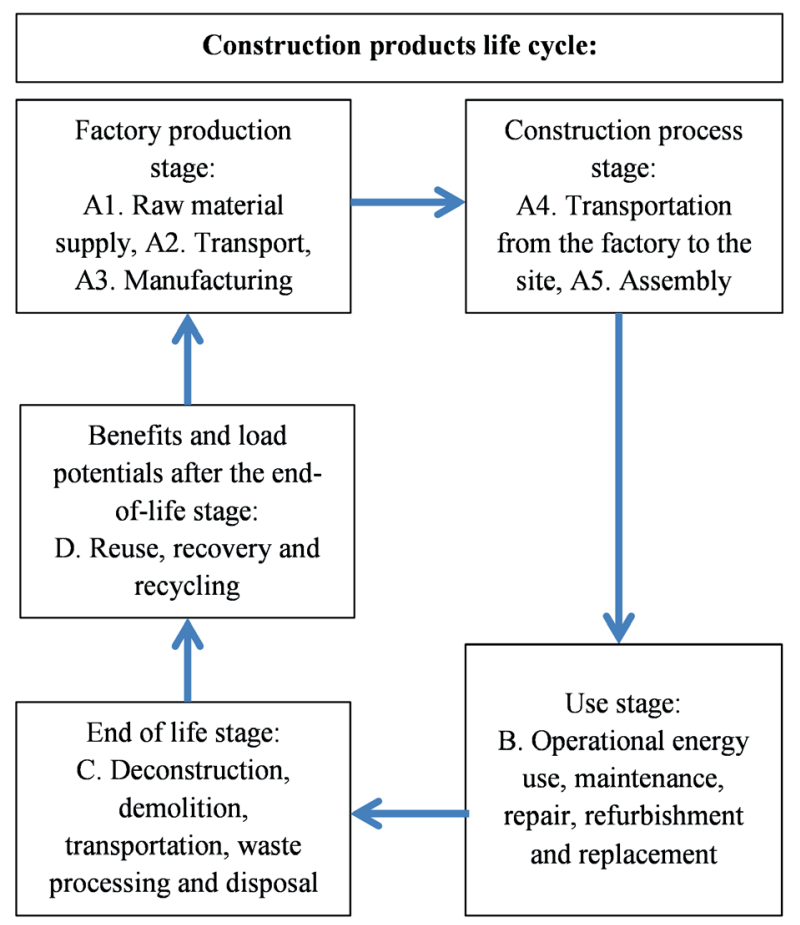

Fig. 4. The cycles of stages in construction products life

a circular economy, where the value of resources can be recovered after the end of life and can be maintained in the economy. This is the recoverable part of embodied energy. 


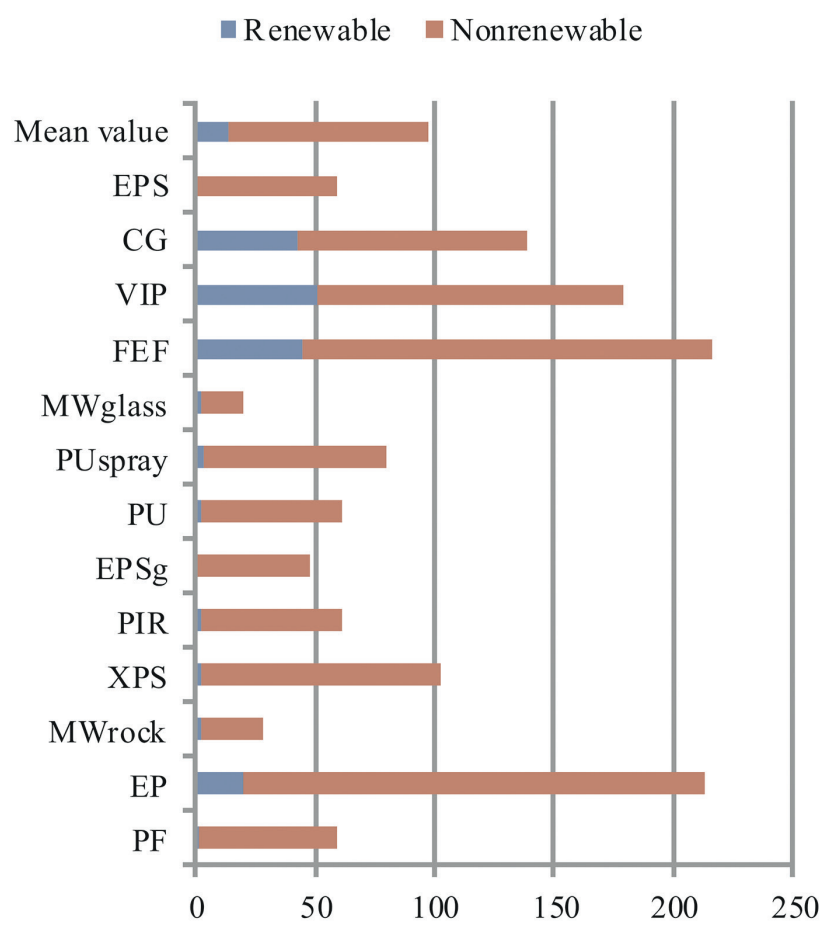

Total use of primary energy per thermal resistance for A1-A3 modules, $\mathrm{MJ} /\left(\mathrm{m}^{2} \mathrm{~K} / \mathrm{W}\right)$

Fig. 5. The results of the assessment according to EPD for several categories of thermal insulation construction products for factory production stage

The energy indicator value can also be determined for a specific unit, relevant for the typical use of a construction product, e.g. thermal resistance $\left(\mathrm{m}^{2} \mathrm{~K} / \mathrm{W}\right)$ for thermal insulation products.

Fig. 5 shows the results of the assessment of modules A1-A3, according to Environmental Product Declarations (EPD) for several different thermal insulation construction products available on the European market in the following types:

- expanded polystyrene (EPS),

- cellular glass (CG),

- vacuum insulation panels (VIP),

- flexible elastomeric foam (FEF),

- mineral glass wool (MWglass),

- in-situ formed sprayed rigid polyurethane (PUspray),

- polyurethane foam (PU),

- expanded polystyrene with graphite addition (EPSg),

- polyisocyanurate foam (PIR),

- extruded polystyrene foam (XPS),

- mineral rock wool (MWrock),

- expanded perlite (EP),

- phenolic foam (PF).

Fig. 6 shows the results of the assessment for module D, however, for a number of product types, the declaration of energy indicator values is not used.

For a given sample, the mean value of the total primary energy for the factory production stage per thermal resistance

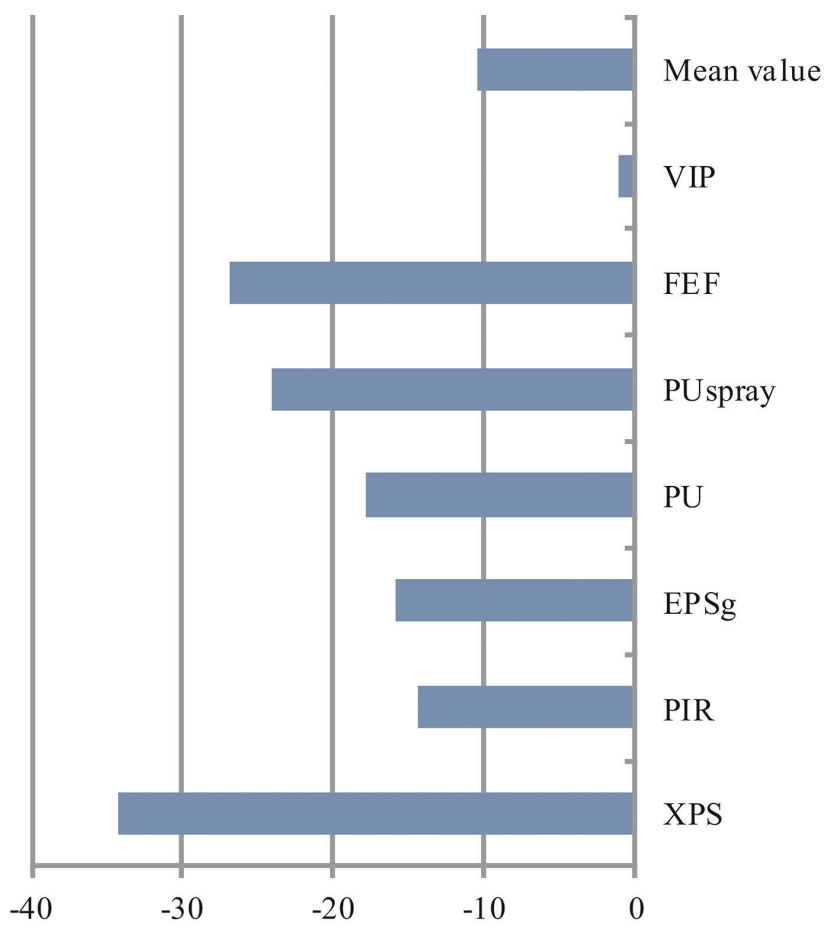

Potential of primary energy recovery per thermal resistance for $D$ module, $\mathrm{MJ} /\left(\mathrm{m}^{2} \mathrm{~K} / \mathrm{W}\right)$

Fig. 6. The results of the assessment according to EPD for several categories of thermal insulation construction products: benefits after the end-of-life stage (potential for energy recovery)

unit is nearly $100 \mathrm{MJ} /\left(\mathrm{m}^{2} \mathrm{~K} / \mathrm{W}\right)$, with less than $15 \%$ of it coming from renewable sources. For products for which the potential of primary energy recovery has been declared, the average value is nearly $10 \mathrm{MJ} /\left(\mathrm{m}^{2} \mathrm{~K} / \mathrm{W}\right)$. In current practice, energy indicator values for construction products are usually determined excluding the use stage (Modules B), since this part is incorporated into the evaluation of a building's energy characteristic according to European regulations [38, 39]. Fig. 7 shows steps of the cost-optimal methodology framework.

Global costs expressed in monetary units are calculated as follows:

$$
\mathrm{C}_{\mathrm{g}}(\tau)=\mathrm{C}_{\mathrm{I}}+\sum_{\mathrm{j}}\left[\sum_{\mathrm{i}}^{\tau} \mathrm{C}_{\mathrm{a}, \mathrm{i}, \mathrm{j}} \mathrm{R}_{\mathrm{d}, \mathrm{j}}+\mathrm{C}_{\mathrm{CO}_{2}, \mathrm{i}, \mathrm{j}}-\mathrm{V}_{\mathrm{f}, \tau, \mathrm{j}}\right]
$$

where:

$\tau-$ is the calculation period, in years;

$C_{I}-$ is the initial investment cost for the variant of measures $j$, in monetary units;

$\mathrm{C}_{\mathrm{a}, \mathrm{i}, \mathrm{j}}$ - is the annual cost during year $\mathrm{i}$ for the variant of measures $\mathrm{j}$, in monetary units;

$R_{d, j}$ - is the dimensionless discount factor for year $i$ based on the discount rate;

$\mathrm{C}_{\mathrm{CO}_{2}, \mathrm{i}, \mathrm{j}}$ - is the discounted $\mathrm{CO}_{2}$ equivalent emissions cost for the variant of measures $j$ during year $i$, in monetary units;

$\mathrm{V}_{\mathrm{f}, \mathrm{t}, \mathrm{j}}$ - is the discounted residual value for set of measures $\mathrm{j}$ at the end of the calculation period, in monetary units. 
1. Establishment of a reference for new and existing buildings for the typical categories, e.g. residential buildings, commercial buildings, etc

2. Identification of variants and packages of energy efficiency measures, including based on renewable energy sources

3. Calculation of the primary energy demand resulting from the application of such variants and packages of measures

4. Calculation of the global cost in terms of net present value (NPV) for reference buildings

5. Undertaking of a sensitivity analysis for cost input data

6. Derivation of the cost-optimal level of energy performance for reference buildings

Fig. 7. The steps of the cost-optimal methodology framework

The result of the calculation is the optimal cost for energy performance requirements. Fig. 8 provides an example of the method for a specific reference type of building in Poland, an existing hospital building subject to modernization.

Due to the uncertainty of input data for the global cost determination, i.e. energy price development scenarios for energy commodities and changes over the time of the discount rate,

\section{Global cost (PLN/m²}

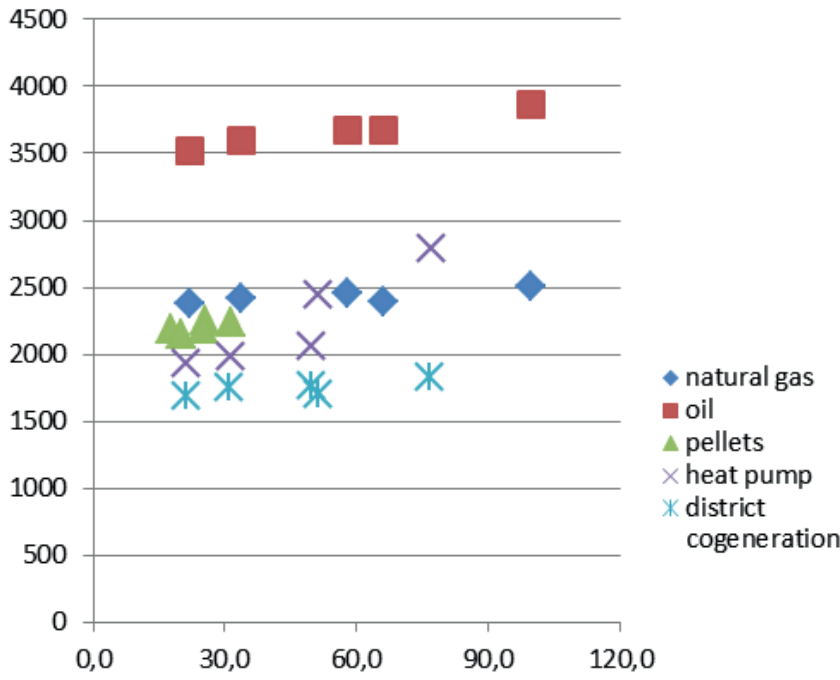

Primary energy indicator (space heating), $\left(\mathrm{kWh} / \mathrm{m}^{2} \mathrm{a}\right)$

Fig. 8. An example of the determination of the cost optimal level of the primary energy for the selected category of buildings in Poland - existing hospital building which is subject to modernisation (five different packages of measures and five different of types of energy commodities) [40] sensitivity analysis can be performed to assess the propagation of uncertainty on final results [41].

The energy characteristic of a building is defined as the amount of energy demand associated with the typical use of the building. Within the defined system boundaries energy can be delivered or exported. Energy losses in the technical systems of the building are explicitly taken into account. Outside of the system boundaries, energy losses are taken into account through the primary energy factors established at state level. Energy commodities, which cover both fuel as well as heat and power (electricity) from on-site renewables, are characterised by the lowest values, followed by off-site renewables and non-renewables (the highest value of the factor is applied for the grid mix electricity).

The list of primary energy factors for Germany (total and for non-renewable) and Poland (only for non-renewable factors) are shown in Fig. 9 [40, 42].

\section{Nonrenewable primary energy factor - Poland \\ - Nonrenewable primary energy factor - Germany \\ - Total primary energy factor - Germany}

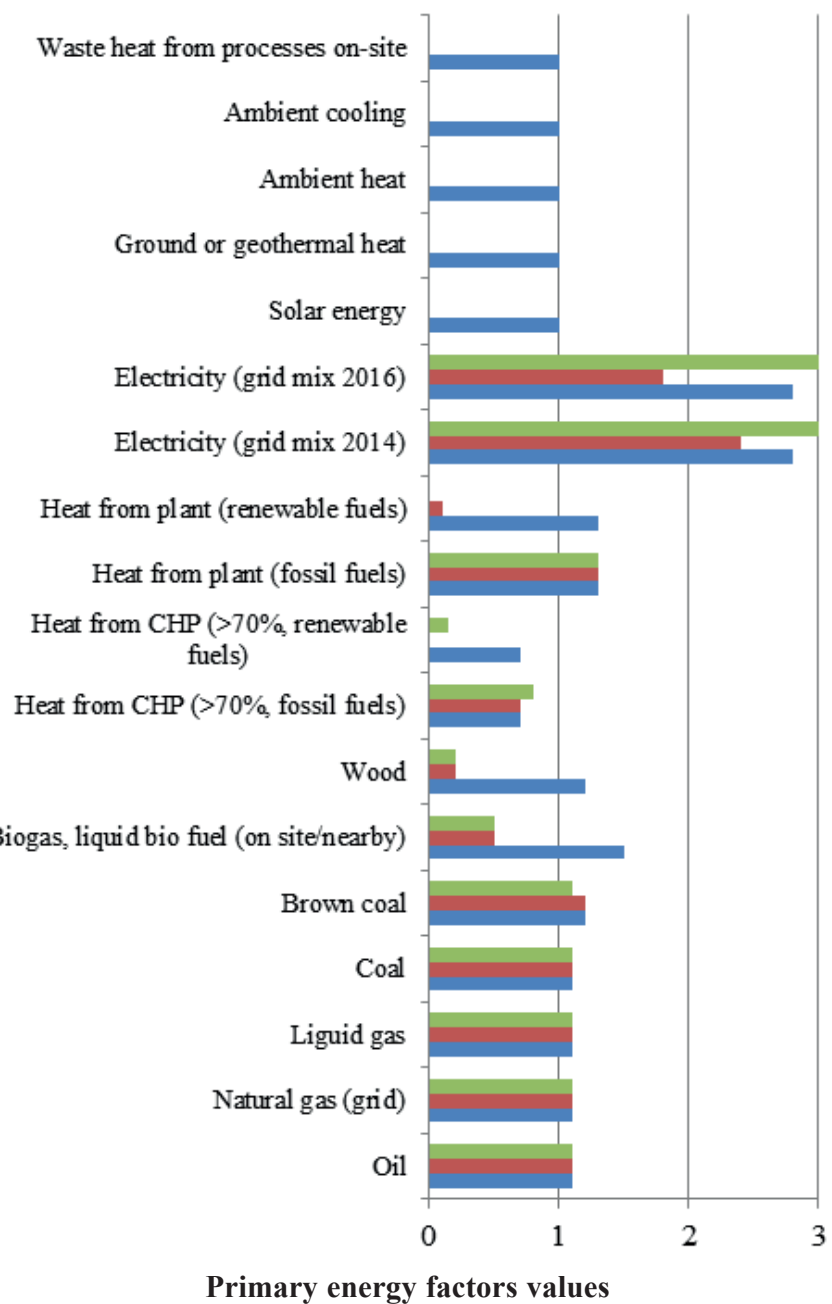

Fig. 9. Primary energy factors for Germany (total and for non-renewable) and Poland (only for non-renewable factors) 
The energy indicator expressed e.g. in $\mathrm{kWh} / \mathrm{m}^{2} \mathrm{a}$ of the building is calculated as follows [43]:

$$
\mathrm{E}_{\mathrm{P}}=\sum_{\mathrm{i}} \mathrm{E}_{\mathrm{D}, \mathrm{i}} \mathrm{f}_{\mathrm{i}}-\sum_{\mathrm{i}} \mathrm{E}_{\mathrm{E}, \mathrm{i}} \mathrm{f}_{\mathrm{i}}
$$

where:

$E_{D, i}-$ is the delivered energy for energy commodity ' $\mathrm{i}$ ', e.g. in $\mathrm{kWh} / \mathrm{m}^{2} \mathrm{a}$;

$E_{E, i}-$ is the exported energy for energy commodity ' $i$ ', e.g. in $\mathrm{kWh} / \mathrm{m}^{2} \mathrm{a}$;

$f_{i}-$ is dimensionless the primary energy factor for energy commodity 'i'.

The direction of calculation is from the building's energy needs to the primary energy. There are passive and active mea- sures for the reduction of energy needs. Electrical services (lighting, ventilation, auxiliary) and thermal services (heating, cooling, domestic hot water) are considered separately inside the building. For the various technical energy systems, a calculation can be performed using annual or monthly average values. The relationship between energy performance calculation components is shown in Fig. 10.

In voluntary environmental certification systems, the assessment of the development in the energy performance of buildings is based on inspecting improvements that go above national building regulations. The evaluation of such relative improvements is used in the LEED certification system [44]. This approach is based on the building's reference energy performance. The minimum level of energy efficiency is established in the

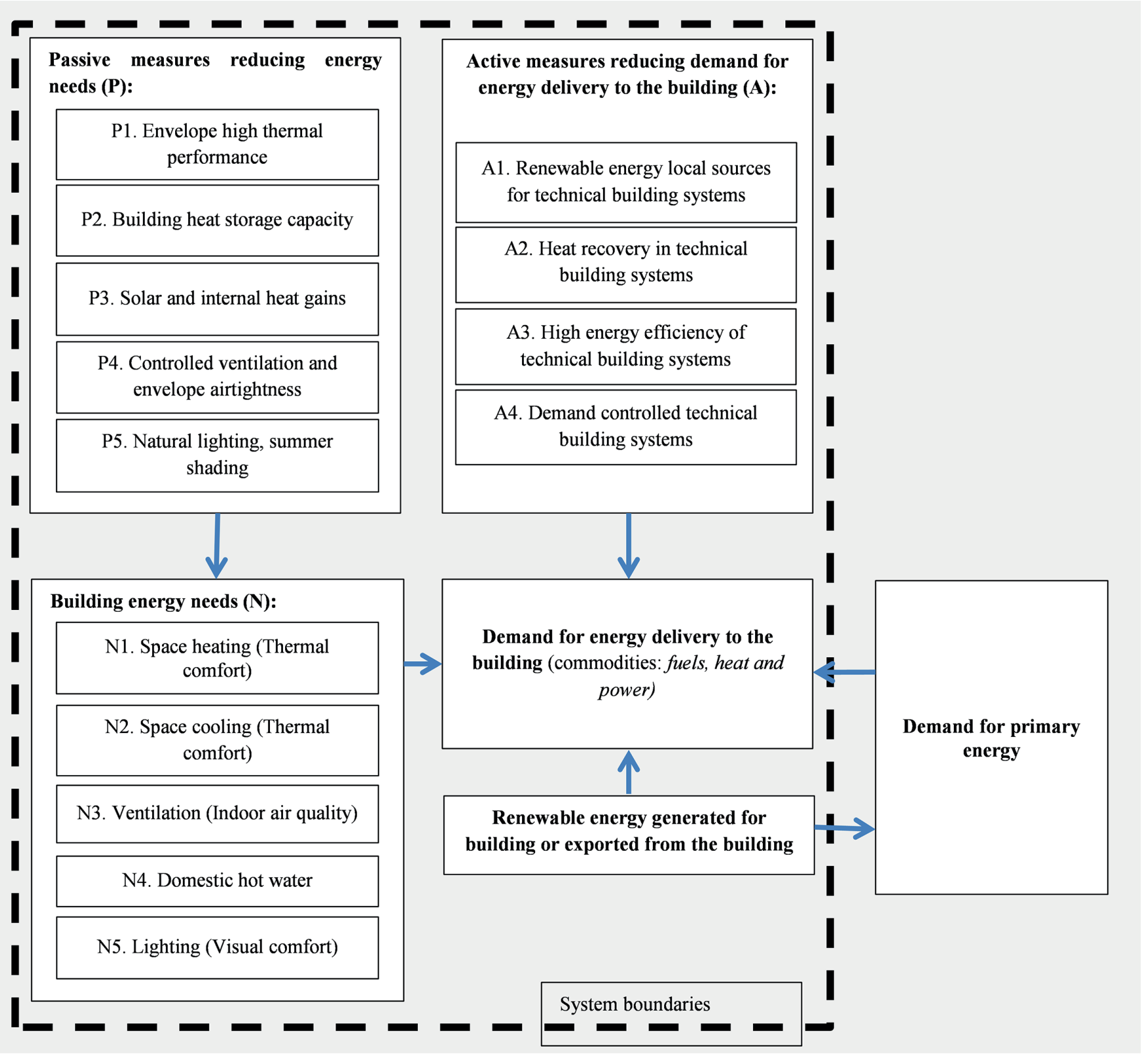

Fig. 10. The relationship between energy performance calculation components 
form of a percentage improvement in the building's proposed performance ("a representation of the building's proposed design used as the basis for calculating the design's energy cost") compared with the baseline building performance ("a digital representation of a hypothetical design") according to regulations. In the U.S., minimum energy efficiency requirements for newly constructed federal buildings - commercial and residential - have been set out in the standard [45]. In this approach, a baseline for energy related costs is determined using building energy simulation [46, 47].

In the LEED evaluation, total energy demand includes the needs for heating, ventilation, air conditioning (HVAC), lighting and for domestic water heating. The process energy includes office and general miscellaneous equipment in the building e.g. computers, elevators, waterfall pumps. There are also other energy related aspects in the LEED certification system concerning peak energy demand, energy metering, use of energy management systems and energy from renewable sources.

The improvements in the energy performance of the building above national building regulations is also recognised in the BREEAM certification system, which first evaluates heating and cooling energy demands. The BREEAM schemes stimulate reductions in $\mathrm{CO}_{2}$ emissions through rewarding good practice and the implementation of individual energy-saving measures $[48,49]$.

\section{Energetic properties of the building envelope}

According to the measures hierarchy, the basic measure is reducing site energy demand through building technologies. The high thermal performance of the building envelope (the building fabric) and the capability of buildings to store heat are two energetic conditions necessary for the building's thermal stability and the effective utilisation of heat gains (solar and internal) in the heating season resulting in the lowering of the energy demand. The building energy needs are also influenced by other envelope parameters, such as the airtightness (having an influence on uncontrolled air exchange) and the total solar energy transmittance for transparent elements and solar protection devices against overheating.

The thermal stability of the building envelope can be defined as the ability to keep the internal surface temperature within acceptable limits, taking into account varying external and internal conditions, including changes in climate conditions (air temperature and solar radiation) and the time-varying operation of space heating or cooling systems. The thermal resistance and thermal capacity of partitions have a significant influence on lowering the systems peak power and the potential of thermal storage, including for instance, night cooling during the summer, which involves intensive night ventilation of the building in order to protect it against the daily fluctuation in air temperature.

Most modern building envelope structures represent complex three-dimensional objects consisting of structural and filling elements. For this reason, the thermal performance of

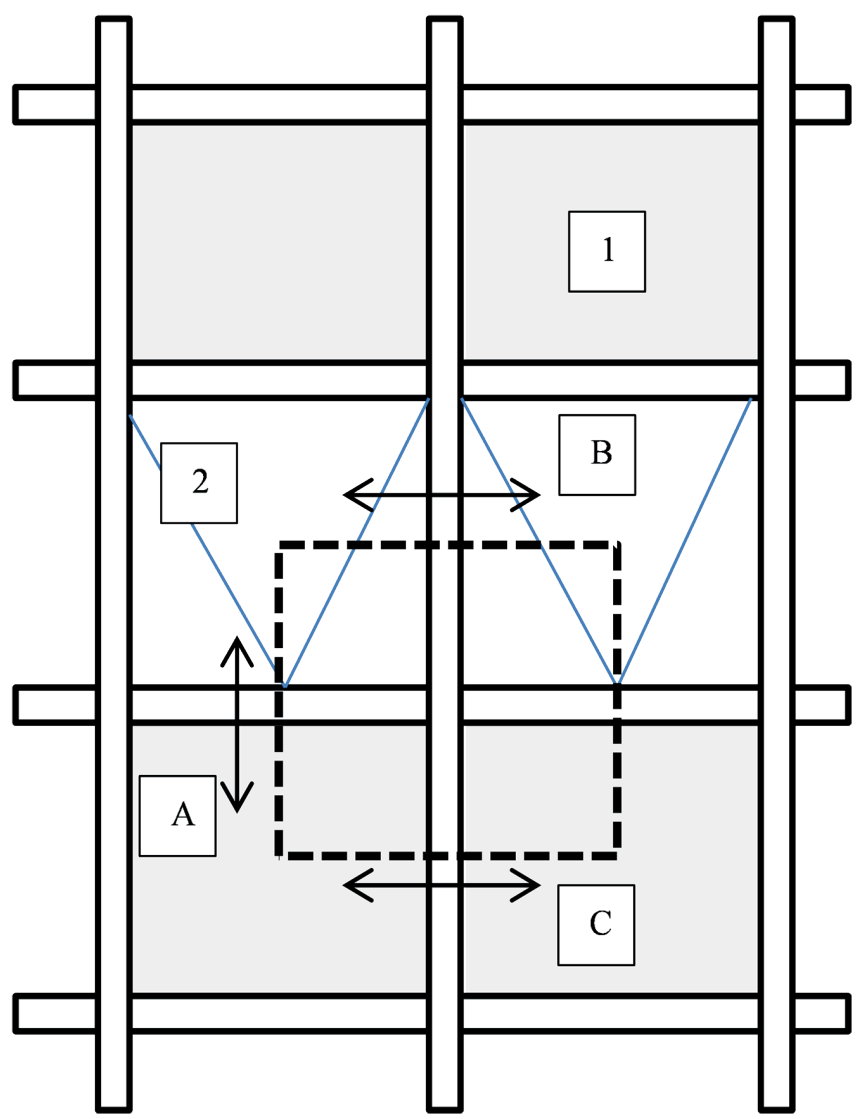

Fig. 11. Sections A, B and C and two types of filling elements: 1 - opaque, 2 - transparent

the building envelope, which contains various opaque and transparent components, is determined by modelling the envelope which is partitioned into several sections by using cut-off planes between adiabatic boundaries, so that the thermal transmittance of the overall envelope can be obtained as the area weighted average of the thermal transmittance of filling elements, with additional corrective terms describing the thermal interaction between the elements in each section (Fig. 11). This method can be used for any walling and roofing systems (e.g. unitised systems, stick systems, structural sealant glazing, structural glazing and other types of curtain walling) [50].

For each section, numerical modelling of the heat transfer through a complete part of the envelope including structural elements, e.g. mullions, transoms and filling elements - such as glazing units or opaque panels - can be applied. Since in most cases, it is difficult to separate heat flowing through structural elements and filling elements, the total heat flow rate $\Phi_{\text {tot }}$ expressed in $\mathrm{W}$ is calculated using three-dimensional temperature field modelling and includes:

- heat flow rate through filling elements $\left(\Phi_{\mathrm{FE}}\right.$, one-dimensional heat flows perpendicular to the surface of the filling elements);

- heat flow rate $\Phi_{\mathrm{SE}}$ through the structural element including edge heat flows due to the thermal interaction between the filling elements and the structural elements. 


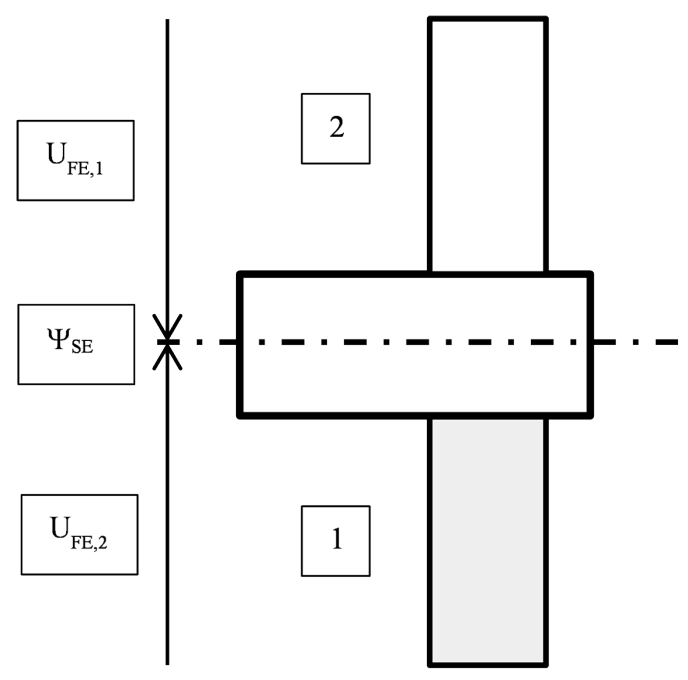

Fig. 12. The area-related thermal transmittance of filling elements $\mathrm{U}_{F E}$ and length-related linear thermal transmittance $\Psi_{S E}$ in sections A

In a steady state of heat transfer (at the constant temperature difference $\Delta \theta$ between internal and external environments expressed in $\mathrm{K}$ ), the heat transfer coefficient $\mathrm{H}_{\text {tot }}$ can be considered in terms of the area-related $\left(\mathrm{A}_{\mathrm{FE}}\right.$ in $\left.\mathrm{m}^{2}\right)$ thermal transmittance of filling elements $\mathrm{U}_{\mathrm{FE}}$ expressed in $\mathrm{W} / \mathrm{m}^{2} \mathrm{~K}$ and length-related ( $1_{\mathrm{SE}}$ in $\mathrm{m}$ ) linear thermal transmittance $\Psi_{\mathrm{SE}}$ expressed in $\mathrm{W} / \mathrm{m} \times \mathrm{K}$ (Fig. 12).

$$
\mathrm{H}_{t o t}=\Psi_{S E} l_{S E}+\sum_{\mathrm{i}} U_{F E, i} A_{F E, i}
$$

The formula is valid only for a steady state of heat transfer. For analysis of transient heat transfer numerical modeling of dynamic temperature fields is needed to assess the effects of heat storage. The energy balance method is used for all control volumes around the material nodes of numerical model of a complete part of the envelope including structural elements, e.g. mullions, transoms and filling elements. In such a model, latent heat and the material volume heat capacity is taken into account.

The general review of results reported by other authors gives examples of the effect of applications in building's envelope an aerogel based thermal insulation for higher thermal transmittance and a phase change material for higher latent heat capacity.

At present, the thermal transmittance of the envelope elements for the European construction sector varies from less than $2.0 \mathrm{~W} / \mathrm{m}^{2} \mathrm{~K}$ for typical technical solutions of curtain walling (e.g. maximum thermal transmittance of curtain walling for dwellings in England is $2.0 \mathrm{~W} / \mathrm{m}^{2} \mathrm{~K}$, maximum average Uvalues for new residential buildings in Germany from $1^{\text {st }}$ January 2016 for curtain walls is $1.5 \mathrm{~W} / \mathrm{m}^{2} \mathrm{~K}$ ) to less than $0.8 \mathrm{~W} / \mathrm{m}^{2} \mathrm{~K}$ in the case of passive buildings applications. However, both opaque and transparent filling elements can usually be characterised by high thermal resistance, due to the use of thick thermal insulation layers and the use of insulated glass units, typical structural elements that can significantly increase the thermal transmittance of the whole components.

One of the possible measures to improve thermal resistance of this part of the structure is the application of aerogel-based thermal insulation materials as a thermal break between filling elements [51].

As a result of the implementation of new requirements concerning thermal transmittance of envelope parts (e.g. less than $0.15 \mathrm{~W} / \mathrm{m}^{2} \mathrm{~K}$ for walls in passive buildings) aerogel based thermal insulation materials are regarded as one of the most advanced products for the construction sector with low thermal conductivity and the possibility for transmittances in the solar spectrum, used also in panels by applying low-pressure to an aerogel material $[52,53]$.

The building envelope thermal properties are assessed and conditioned not only in terms of thermal performance, which refers to the constant thermal conditions, but also in terms of the sensitivity to changes in these conditions over time.

For complex structures, dynamic two-dimensional or three-dimensional temperature field modelling can be used for the determination of equivalent elements, which have the same dynamic thermal behaviour for use in transient energy simulation software, capable of modelling the whole building energy need, but where the heat flow through the envelope is usually regarded as a one-dimensional transient (e.g. TRNSYS, EnergyPlus software). In dynamic analysis, a finite difference or finite elements modelling is used for each of the two- or three-dimensional elements [54-57].

A study of the dynamic properties of building partitions is often undertaken on account of the introduction of new construction materials and products, used in place of traditional types of construction, e.g. based on PCM for achieving higher thermal stability and reducing indoor air temperature fluctuations. This paper has followed a number of other authors in considering issues related to the impact of the thermal capacity, latent heat thermal storage (LHTS), the optimal melting temperatures of PCM, the optimum layouts and dimensions of the material layers. Based on literature results systems with PCM for heat storage have been recognised as one of the advanced technologies for passive and active building applications [18, 58-61]. The range of applications covers envelope parts and different applications for buildings technical systems [62, 63]. The effect of PCM layer thickness and phase-change temperature on the thermal storage behaviour has been analysed using whole building dynamic simulation as well as whole life-cycle cost and energy analysis [64-69].

\section{Conclusions}

Energy-related conditions are crucial for the implementation of sustainable development in the construction and building sector. However, there is no univocally established definition of sustainable development, and different emphasis is put on either development or sustainability aspects of energy performance. In the sustainability dimension, international standardisation is based on the life cycle assessment of environmental, social 
and economic performances where main energy related aspects have been represented by:

- primary energy demand and energy use related greenhouse emissions (environmental sub-dimension);

- required indoor comfort: thermal, visual and air quality (social sub-dimension);

- life-cycle cost (economic sub-dimension).

The development aspects are subject to requirements, both obligatory at State level, and voluntary, as part of environmental certification systems. The optimisation leading to the determination of the minimum value of the building's energy performance which meets social performance requirements resulting in the minimum value of life-cycle cost and environmental impacts can be considered the link between sustainability and development dimensions.

Several definitions of zero energy buildings have been proposed in the literature:

- life-cycle zero energy buildings (LC-ZEB),

- net zero energy buildings (Net ZEB),

- nearly zero-energy buildings (NZEB).

The energy-related options hierarchy as the primary measure provides for reducing the building's energy requirement through high thermal performance of the building envelope and building heat storage potential.

For many modern building envelope structures, which represent complex three-dimensional objects consisting of structural and filling elements, the dynamic two-dimensional or three-dimensional temperature fields modelling have to be used. For complex walling and roofing systems, more advanced technologies in enhancing energy efficiency of buildings are systems based on aerogel thermal insulation materials, e.g. applied as a thermal break between filling elements and phase change materials for achieving higher thermal stability of a structure, for heat storage and release of heat within a certain temperature range.

Extensive research efforts have been undertaken in these fields but the dynamic behaviour of the combined use of the aforementioned technologies needs further investigation for most complex walling structures resulting in non-one-dimensional heat transfer through a complete part of the envelope including structural elements and filling elements.

\section{REFERENCES}

[1] T. Ramesh, R. Prakash, K.K. Shukla, "Life cycle energy analysis of buildings: An overview", Energy and Buildings 42 (10), 1592-1600 (2010).

[2] W. K. Biswas, "Carbon footprint and embodied energy consumption assessment of building construction works in Western Australia”, International Journal of Sustainable Built Environment, 3 (2), 179-186 (2014).

[3] C. Thormark, "A low energy building in a life cycle-its embodied energy, energy need for operation and recycling potential", Building and Environment 37 (4), 429-435 (2002).

[4] P. Chastas, T. Theodosiou, D. Bikas, "Embodied energy in residential buildings-towards the nearly zero energy building: A literature review", Building and Environment 105, 267-282 (2016).
[5] R. H. Crawford, E. L. Bartak, A. Stephan, C. A. Jensen, "Evaluating the life cycle energy benefits of energy efficiency regulations for buildings", Renewable and Sustainable Energy Reviews 63, 435-451 (2016).

[6] A.J. Marszal, P. Heiselberg, J.S. Bourrell, E. Musall, K. Voss, I. Sartori, A. Napolitano, "Zero energy building - A review of definitions and calculation methodologies", Energy and Buildings 43 (4), 971-979 (2011).

[7] P. Hernandez, P. Kenny, "From net energy to zero energy buildings: Defining life cycle zero energy buildings (LC-ZEB)", Energy and Buildings, 42 (6), 815-821 (2010).

[8] I. Sartori, A. Napolitano, K. Voss, "Net zero energy buildings: A consistent definition framework", Energy and Buildings 48 ,220-232 (2012).

[9] P. Torcellini, S. Pless, M. Deru, D. Crawley, "Zero energy buildings: A critical look at the definition", ACEEE Summer Study, California, August 14-18, 2006.

[10] A. J. Marszal, P. Heiselberg, R. L. Jensen, J. Nørgaard, “Onsite or off-site renewable energy supply options? Life cycle cost analysis of a Net Zero Energy Building in Denmark", Renewable Energy 44, 154-165 (2012).

[11] S. B. Sadineni, S. Madala, R. F. Boehm, "Passive building energy savings: A review of building envelope components", Renewable and Sustainable Energy Reviews 15 (8), 3617-3631 (2011).

[12] E. Cuce, P. M. Cuce, C. J. Wood, S. B. Riffat, "Toward aerogel based thermal superinsulation in buildings: A comprehensive review", Renewable and Sustainable Energy Reviews 34, 273-299 (2014).

[13] R. Baetens, B. P. Jelle, A. Gustavsen, "Aerogel insulation for building applications: A state-of-the-art review", Energy and Buildings 43 (4), 761-769 (2011).

[14] R. Baetens, B. P. Jelle, J. V. Thue, M. J. Tenpierik, S. Grynning, S. Uvsløkk, A. Gustavsen, "Vacuum insulation panels for building applications: A review and beyond", Energy and Buildings 42 (2), 147-172 (2010).

[15] M. Alam, H. Singh, M. C. Limbachiya, "Vacuum Insulation Panels (VIPs) for building construction industry - A review of the contemporary developments and future directions", Applied Energy 88 (11), 3592-3602 (2011).

[16] A. Kylili, P. A. Fokaides, "Life Cycle Assessment (LCA) of Phase Change Materials (PCMs) for building applications: A review”, Journal of Building Engineering 6, 133-143 (2016).

[17] Y. Konuklu, M. Ostry, H. O. Paksoy, P. Charvat, "Review on using microencapsulated phase change materials (PCM) in building applications", Energy and Buildings 106, 134-155 (2015).

[18] M. Iten, S. Liu, A. Shukla, "A review on the air-PCM-TES application for free cooling and heating in the buildings", Renewable and Sustainable Energy Reviews 61, 175-186 (2016).

[19] L. Czarnecki, J. J. Sokołowska "Material model and revealing the truth". Bull. Pol. Ac.: Tech. 63 (1), 7-14 (2015).

[20] D. Gawin, M. Koniorczyk, F. Pesavento "Modelling of hydro-thermo-chemo-mechanical phenomena in buildings materials", Bull. Pol. Ac.: Tech. 61 (1), 51-64 (2013).

[21] S. Woliński "Defining of the structural robustness", Bull. Pol. Ac.: Tech. 61 (1), 137-144 (2013).

[22] L. Czarnecki, M. Kapron, "Sustainable Construction as a Research Area", International Journal of the Society of Materials Engineering for Resources 17 (2), (2010).

[23] P. M. Boulanger, "Sustainable development indicators: a scientific challenge, a democratic issue", S.A.P.I.EN.S 1 (1), (2008). 
[24] Report of the World Commission on Environment and Development: Our Common Future, Transmitted to the General Assembly as an Annex to document A/42/427 - Development and International Co-operation: Environment, UN Documents, 1987.

[25] United Nations Conference on Environment \& Development Rio de Janerio, Brazil, 3 to 14 June 1992, AGENDA 21, UN Documents, 1992

[26] Resolution adopted by the General Assembly on 27 July 2012, 66/288. The future we want, UN Documents, 2012.

[27] Resolution adopted by the General Assembly on 25 September 2015, 70/1. Transforming our world: the 2030 Agenda for Sustainable Development, UN Documents, 2015.

[28] Agenda 21 on sustainable construction, CIB Report Publication 237, 1999

[29] M. Piasecki, R. Geryło, "Economic analysis of buildings in their life cycle - calculation methods and examples", XIV-th Polish Scientific-Technical Conference on Building Physics in Theory and Practice (2013) [in Polish]

[30] EN 15643-1:2010 Sustainability of construction works - Sustainability assessment of buildings - General framework.

[31] EN 15643-2:2011 Sustainability of construction works - Assessment of buildings -Framework for the assessment of environmental performance.

[32] EN 15643-3:2012 Sustainability of construction works - Assessment of buildings - Framework for the assessment of social performance.

[33] EN 15643-4:2012 Sustainability of construction works - Assessment of buildings - Framework for the assessment of economic performance.

[34] EN 15978:2011 Sustainability of construction works - Assessment of environmental performance of buildings - Calculation method.

[35] EN 16309:2014 Sustainability of construction works - Assessment of social performance of buildings - Methods.

[36] EN 16627:2015 Sustainability of construction works - Assessment of economic performance of buildings - Calculation methods.

[37] EN 15804:2012 Sustainability of construction works - Environmental product declarations - Core rules for the product category of construction products

[38] Directive 2010/31/EU of the European Parliament and of the Council of 19 May 2010 on the energy performance of buildings (recast), Official Journal of the European Union L 153/13, 18.6.2010

[39] Commission delegated regulation (EU) No 244/2012 of 16 January 2012 supplementing Directive 2010/31/EU of the European Parliament and of the Council on the energy performance of buildings by establishing a comparative methodology framework for calculating cost-optimal levels of minimum energy performance requirements for buildings and building elements, Official Journal of the European Union, L 81/18, 2012.

[40] R. Gerylo, "The economic optimum of energy requirements for buildings in Poland", 61-th Scientific Conference of the Civil and Water Engineering of the Polish Academy of Science (PAN) and of the Science Committee PZITB, Bydgoszcz - Krynica, Problem part: Energy-saving construction in Poland-current state and perspectives, 2015 [in Polish].

[41] M. Basinska, H. Koczyk, E. Szczechowiak, "Sensitivity analysis in determining the optimum energy for residential buildings in Polish conditions", Energy and Buildings 107, 307-318 (2015).
[42] H. P. Schettler-Köhler, "Implementation of the EPBD in Germany, 2016 - Implementing the Energy Performance of Buildings Directive (EPBD) Featuring Country Reports", ADENE, 2015.

[43] EN 15603:2008 Energy performance of buildings - Overall energy use and definition of energy ratings.

[44] LEED v4 for Building design and construction, U.S. Green Building Council, 2016.

[45] The Energy Conservation \& Production Act - ECPA, 2014.

[46] ANSI/ASHRAE/IES Standard 90.1-2013 - Energy Standard for Buildings Except Low-Rise Residential Buildings, ASHRAE, 2013.

[47] 2012 International Energy Conservation Code, International Code Council, INC., 2011.

[48] T. Taylor, Assessing carbon emissions in BREEAM, Briefing paper, BRE Global Ltd, 2015.

[49] The Building Regulations 2010, Conservation of fuel and power, Approved document L1A Conservation of fule and power in new dwellings, HM Government, 2013 edition incorporating 2016 amendments.

[50] EN ISO 12631:2012 Thermal performance of curtain walling - Calculation of thermal transmittance.

[51] B. Pietruszka, R. Gerylo, "Implementation of nanoporous thermal insulations to improve the energy efficiency of curtain walling structures", $10^{\text {th }}$ International Conference: Modern building materials, structures and techniques, Vilnus, Lithuania, 255-258 (2010).

[52] R. Baetens, B. P. Jellea, A. Gustavsen, "Aerogel insulation for building applications: A state-of-the-art review", Energy and Buildings 43 (4), 761-769 (2011).

[53] R. Baetens, B. P. Jelle, J. V. Thue, M. J. Tenpierik, S. Grynning, S. Uvsløkka, A. Gustavsen, Vacuum insulation panels for building applications: A review and beyond, Energy and Buildings 42 (2), 147-172 (2010).

[54] D. M. Burch, J. E. Seem, G. N. Walton, B.A. Licitra, "Dynamic evaluation of thermal bridges in a typical office building", ASHRAE Transactions 98, 291-304 (1992).

[55] E. Kossecka, J. Kośny, "Three-dimensional conduction z-transfer function coefficients determined from the response factors", $E n$ ergy and Buildings 37 (4), 301-310 (2005).

[56] J. Quinten, V. Feldheim, "Dynamic modelling of multidimensional thermal bridges in building envelopes: Review of existing methods, application and new mixed method", Energy and Buildings 110, 284-293 (2016).

[57] K. Martin, C. Escudero, A. Erkoreka, I. Flores, J. M. Sala, "Equivalent wall method for dynamic characterisation of thermal bridges", Energy and Buildings 55, 704-714 (2012).

[58] N. Zhu, Z. Ma, S. Wang, "Dynamic characteristics and energy performance of buildings using phase change materials: A review"; Energy Conversion and Management 50 (12), 3169-3181 (2009).

[59] H. Akeiber, P. Nejat, M. Z. A. Majid, M. A. Wahid, F. Jomehzadeh, I. Z. Famileh, J. K. Calautit, B. R. Hughes, S. A. Zaki, "A review on phase change material (PCM) for sustainable passive cooling in building envelopes", Renewable and Sustainable Energy Reviews 60, 1470-1497 (2016).

[60] F. Kuznik, D. Davida, K. Johannes, J. J. Roux, "A review on phase change materials integrated in building walls", Renewable and Sustainable Energy Reviews 15 (1), 379-391 (2011).

[61] R. Baetensa, B. P. Jellea, A. Gustavsend, "Phase change materials for building applications: A state-of-the-art review", Energy and Buildings 42 (9), 1361-1368 (2010). 
[62] V. V. Tyagia, S. C. Kaushika, S. K. Tyagib, T. Akiyamac, "Development of phase change materials based microencapsulated technology for buildings: A review", Renewable and Sustainable Energy Reviews 15 (2), 1373-1391 (2011).

[63] D. I. Kolaitis, M. A. Founti, "Solar wall enhanced with phasechange materials: a detailed numerical simulation study", Journal Advances in Building Energy Research 10, 1-17 (2016).

[64] D. Heim, "Phase-Change Material modeling within whole building dynamic simulation", ASHRAE Transactions 112 (1), 518-525 (2006).

[65] D. Heim, "Isothermal storage of solar energy in building construction”, Renewable Energy 35 (4), 788-796 (2010).
[66] D. Heim, A. Wieprzkowicz, "Positioning of an isothermal heat storage layer in a building wall exposed to the external environment", Journal of Building Performance Simulation 9 (5), 542-554 (2016).

[67] A.L.S. Chan, "Energy and environmental performance of building façades integrated with phase change material in subtropical Hong Kong", Energy and Buildings 43 (10), 2947-2955 (2011).

[68] M. Saffaria, A. Graciab, S. Ushakb, L. F. Cabezaa, "Economic impact of integrating PCM as passive system in buildings using Fanger comfort model", Energy and Buildings 112, 159-172 (2016).

[69] D. A. Chwieduk, "Some aspects of energy efficient building envelope in high latitude countries", Energy Procedia 57, 1898-1907 (2014). 